Article

\title{
Chemical Profile and Screening of Bioactive Metabolites of Rindera graeca (A. DC.) Bois. \& Heldr. (Boraginaceae) In Vitro Cultures
}

\author{
Konstantia Graikou 1, Harilaos Damianakos ${ }^{1}$, Christos Ganos ${ }^{1}$, Katarzyna Sykłowska-Baranek ${ }^{2}$, \\ Małgorzata Jeziorek ${ }^{2}$, Agnieszka Pietrosiuk ${ }^{2}$, Christos Roussakis ${ }^{3}$ and Ioanna Chinou 1,* \\ 1 Laboratory of Pharmacognosy and Chemistry of Natural Products, Department of Pharmacy, \\ National \& Kapodistrian University of Athens, Zografou, 15771 Athens, Greece; \\ kgraikou@pharm.uoa.gr (K.G.); harisdam@pharm.uoa.gr (H.D.); chris50ganos@hotmail.com (C.G.) \\ 2 Department of Pharmaceutical Biology and Medicinal Plant Biotechnology, Faculty of Pharmacy, \\ Medical University of Warsaw, 1 Banacha, 02-097 Warsaw, Poland; kasiasb@farm.amwaw.edu.pl (K.S.-B.); \\ gosiajeziorek@op.pl (M.J.); agnieszka.pietrosiuk@wum.edu.pl (A.P.) \\ 3 IICi MED/EA 1155- Department Cancer du Poumon et Cbles Moleculaires, UFR Sciences Pharmaceutiques- 9 \\ rue Bias, CEDEX 1, 44035 Nantes, France; christos.roussakis@univ-nantes.fr \\ * Correspondence: ichinou@pharm.uoa.gr
}

Citation: Graikou, K.; Damianakos, H.; Ganos, C.; Sykłowska-Baranek, K.; Jeziorek, M.; Pietrosiuk, A.; Roussakis, C.; Chinou, I. Chemical Profile and Screening of Bioactive Metabolites of Rindera graeca (A. DC.) Bois. \& Heldr. (Boraginaceae) In Vitro Cultures. Plants 2021, 10, 834. https://doi.org/10.3390/ plants10050834

Academic Editor: Marcello Salvatore Lenucci

Received: 5 April 2021

Accepted: 19 April 2021

Published: 21 April 2021

Publisher's Note: MDPI stays neutral with regard to jurisdictional claims in published maps and institutional affiliations.

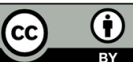

Copyright: (c) 2021 by the authors. Licensee MDPI, Basel, Switzerland. This article is an open access article distributed under the terms and conditions of the Creative Commons Attribution (CC BY) license (http://creativecommons.org/licenses /by/4.0/).

\begin{abstract}
Rindera graeca is a rare endemic plant where in vitro culture has been used in order to investigate bioactive metabolites. Phytochemical study of the in vitro shoots and hairy roots led to the isolation of seven phenolic derivatives and the unusual furano-naphthoquinone rinderol. $R$. graeca was also analyzed for its pyrrolizidine alkaloids content by LC-MS, and it was found to contain echinatine together with echinatine and rinderine N-oxides. Rinderol, isolated only from in vitro hairy root culture for the first time in the genus, revealed promising bioactivities. It was evaluated in vitro against a panel of microorganisms, showing very strong activity specifically against Gram-positive bacteria (MIC values $0.98 \times 10^{-2}-1.18 \mu \mathrm{g} / \mathrm{mL}$ ) as well as very interesting antiproliferative effect against the human non-small-cell bronchopulmonary carcinoma cell line NSCLC-N6-L16 and the epidermoid lung cancer cell line A549. These findings were compared with the chemical profile of the plant from nature, while this study is the first to report on the effects of $R$. graeca extracts obtained from in vitro culture, providing a valuable contribution to the scientific community towards this sustainable method of production of potential bioactive molecules.
\end{abstract}

Keywords: Boraginaceae; Rindera graeca; in vitro culture; hairy roots; caffeic acid derivatives; quercetin 3-rutinoside-7-rhamnoside; pyrrolizidine alkaloids; rinderol; antimicrobial activities; antiproliferative activities

\section{Introduction}

In the framework of the studies of our scientific team on Mediterranean endemic Boraginaceae species [1-9], the genus Rindera Pall. belonging to tribe Cynoglosseae of the borage plant family has attracted our scientific interest [8]. The genus Rindera is comprised of 25 species [10], and is widespread mainly in Europe and Asia. It is characterized as a source of caffeic acid derivatives, flavonoids, and pyrrolizidine alkaloids (PAs) while its seeds are a rich source of fatty acids.

Rindera graeca Boiss \& Heldr. has been studied phytochemically very recently, while its antioxidative properties have been evaluated showing an interesting chemical profile and bioactive potency [8].

As Rindera is a rare species, in this study we were focused on the alternative modern approach of its in vitro culture and towards the phytochemical study of its crude mate- 
rial, which was further analyzed and presented herein. Preliminary in vitro cultures on its roots led to the detection of naphthoquinone shikonin-type metabolites, revealing it as a rich source of caffeic acid derivatives (rosmarinic, lithospermic acids, etc.) [1].

According to the literature, several biotechnological approaches have been used to enhance the production of phenolic compounds in in vitro cultures of plant organs, tissues, and cells [11], especially towards rosmarinic acid (RA) production, which is a well-known chemotaxonomic marker among Boraginaceae plants [7-9]. RA, as an ester of caffeic acid, is often followed by its derivatives, lithospermic acid (LA) and rabdosiin $[5,8]$.

Rindera graeca and Rindera gymnandra are the only endemic Mediterranean taxa in Greece and Algeria, respectively [12]. Other Rindera species endemic in Turkey $(R . d u-$ manii, $R$. caespitosa, and $R$. cetineriare) have been used in folk medicine, appreciated for their anti-inflammatory properties [13]. The essential oil from $R$. lanata var. canescens showed moderate in vitro antimicrobial activity [14], while a methanolic extract of $R$. lanata var. lanata exerted in vitro antivirus property against a human rotavirus [13]. The fruits of the widely distributed $R$. oblongifolia are a rich source of unsaturated fatty acids [15], similar to the aerial parts, roots, and seeds of the endemic Serbian R. umbellata. A number of pyrrolizidine alkaloids (PAs) have been isolated from the same species [10].

PAs are plant toxins associated with disease in livestock and pose a serious health risk to humans, as they may enter the food chain of humans via meat, milk products, and herbal teas [8,16].They are estimated to be produced by $3 \%$ of all flowering species [2] in the form of bases and pyrrolizidine alkaloid N-oxides (PANOs) [17], while they are among the most common secondary metabolites along with phenolic metabolites and naphthazarin pigments in the Boraginaceae family [4], Cynoglossae tribe [2], particularly the Rindera genus $[8,18,19]$.

The increasing market demand for bioactive extracts and pure metabolites of herbal origin led various biotechnological methods and techniques to be further developed towards the production of active secondary metabolites, protecting both the sustainability and biodiversity of the plant kingdom, which is currently of high importance [20]. The aim of this study was to analyze the plant material derived from in vitro cultures of the rare endemic plant Rindera graeca, evaluating its phytochemical potential for the production of phenolic compounds, to determine the PAs content, and to compare the results with those obtained in a recent study of the naturally occurring plant [8].

Furthermore, we evaluated the antimicrobial and cytotoxic properties of plant extracts obtained via biotechnological methods, together with the most promising pure metabolites.

\section{Results and Discussion}

\subsection{Identification and Isolation of Secondary Metabolites}

Chromatographic separation led to the identification of eight metabolites (Table 1): one flavonoid triglycoside (quercetin-3-rutinoside-7-rhamnoside) (Figure 1), together with caffeic acid and its derivatives: chlorogenic acid, rosmarinic acid, lithospermic acid, rabdosiin, and disodium rabdosiin salt, as well as the furano-naphthoquinone rinderol (Figure 1). All of these were structurally determined by NMR and compared with literature data and previously isolated metabolites. Rinderol was identified for the first time in Rindera in vitro cultures [1], while it has previously been determined through modern spectral means from in vitro roots of Cynoglossum columnae (Boraginaceae) [6] by our team, and from natural roots of Onosma paniculata, proposed as naphthofuranin B [21].

All phenolic metabolites have been identified recently from natural plant samples of Rindera graeca [8]. Most of the caffeic acid derivatives have been identified in multiple Boraginaceae species, while rosmarinic acid is a well-known chemotaxonomic marker of the family [7-9]. Rabdosiin, a dimer of rosmarinic acid, and its disodium salt, a nontrivial compound recently isolated from Alkanna sfikasiana [5] and detected in natural plant of $R$. graeca [8], has previously been studied for potential cytotoxic and antiviral activities [11]. 
All plant material obtained by in vitro culture was also analyzed for its pyrrolizidine alkaloid content by LC-MS, following the standard BfR procedure, and it was found to contain echinatine and echinatine $\mathrm{N}$-oxide (Figure 2), which have been identified from many previously studied Rindera species [8,18,19]. Rinderine N-oxide (Figure 2) was also identified, which has previously been found in plants of the Cynoglossae tribe.

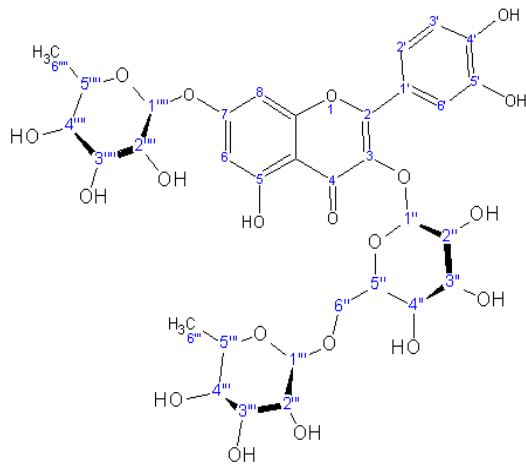

(a)<smiles>COC1=CC(=O)c2c(c(O)cc3cc(CC(C)C)oc23)C1=O</smiles>

(b)

Figure 1. Chemical structure of quercetin 3-rutinoside-7-rhamnoside (a) and rinderol (b).

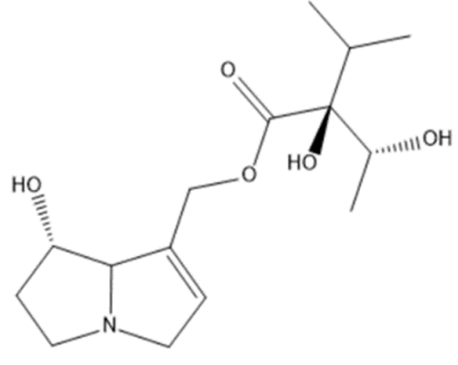

(a)

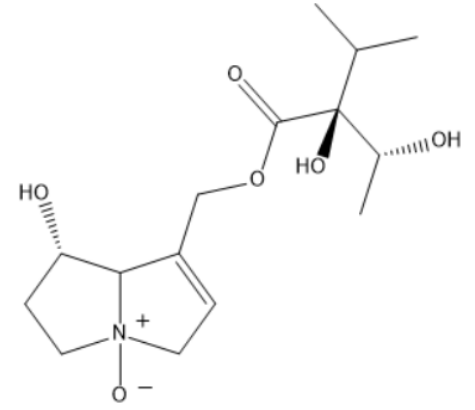

(b)

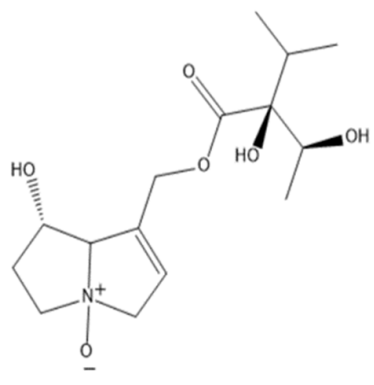

(c)

Figure 2. The structures of identified PA/PANOs: (a) echinatine, (b) echinatine N-oxide, (c) rinderine N-oxide.

Comparing the results of the chemical analyses between cultivated in vitro roots and shoots as well as recently studied naturally occurring aerial parts of $R$. graeca [8] (Table 1), it was revealed that the pyrrolizidine alkaloid content was identical in all three, showing that the in vitro cultures are not Pas free for further application.

Rosmarinic acid, a metabolite with rich biological activity, is commonly found in plants of the Boraginaceae family, serving as a chemotaxonomic marker [7-9]. The metabolites quercetin-3-rutinoside-7-rhamnoside and rabdosiin disodium salt, previously identified from the natural plant, were also isolated. 
Table 1. Comparison of the chemical analyses between in vitro cultures of hairy root in vitro cultures of shoots and aerial parts of the plant in nature.

\begin{tabular}{|c|c|c|c|c|c|}
\hline $\begin{array}{l}\text { Detected/Isolated } \\
\text { Metabolites }\end{array}$ & $m / z$ & $\begin{array}{c}\text { In vitro Cultures } \\
\text { of Hairy Roots }\end{array}$ & $\begin{array}{c}\text { In Vitro Cultures } \\
\text { of Shoots }\end{array}$ & $\begin{array}{c}\text { Natural Aerial } \\
\text { Parts }\end{array}$ & Refs. \\
\hline Lithospermic acid & 537.1161 & V & $\sqrt{ }$ & - & [1] \\
\hline $\begin{array}{c}\text { Lithospermic acid } \\
\text { B }\end{array}$ & 717.1497 & - & - & $\sqrt{ }$ & {$[8]$} \\
\hline Rosmarinic acid & 359.0797 & $\sqrt{ }$ & $\sqrt{ }$ & $\sqrt{ }$ & [8] \\
\hline Chlorogenic acid & 353.0852 & - & $\sqrt{ }$ & $\sqrt{ }$ & [8] \\
\hline Caffeic acid & 179.0321 & - & $\sqrt{ }$ & $\sqrt{ }$ & [8] \\
\hline Salvianolic acid A & 493.0985 & - & - & $\sqrt{ }$ & {$[8]$} \\
\hline $\begin{array}{l}\text { Rabdosiin disodi- } \\
\text { um salt }\end{array}$ & 741.1369 & - & $\sqrt{ }$ & $\sqrt{ }$ & \multirow[t]{2}{*}[5,8]{} \\
\hline Rabdosiin & 717.1391 & - & $\sqrt{ }$ & $\sqrt{ }$ & \\
\hline Rinderol & 301.1082 & $\sqrt{ }$ & - & - & [6] \\
\hline $\begin{array}{l}\text { Quercetin } \\
\text { 3-rutinoside }\end{array}$ & 609.1445 & & - & $\sqrt{ }$ & \multirow[b]{2}{*}[8]{} \\
\hline $\begin{array}{c}\text { Quercetin } \\
\text { 3-rutinoside-7-rha } \\
\text { mnoside }\end{array}$ & 755.2013 & $\sqrt{ }$ & $\sqrt{ }$ & $\sqrt{ }$ & \\
\hline $\begin{array}{c}\text { Echinatine } \\
\end{array}$ & 300.1812 & $\sqrt{ }$ & $\sqrt{ }$ & $\sqrt{ }$ & \multirow{3}{*}[8,10,19]{} \\
\hline Echinatine N-oxide & 316.1768 & $\sqrt{ }$ & $\sqrt{ }$ & $\sqrt{ }$ & \\
\hline Rinderine N-oxide & 316.1756 & $\sqrt{ }$ & $\sqrt{ }$ & $\sqrt{ }$ & \\
\hline
\end{tabular}

\subsection{Cytotoxic Effects}

The cytotoxic activity of rinderol (Figure 1), as well as n-hexane extracts derived from post-culture media of $R$. graeca root cultures, was determined against two human lung cancer cell lines: the human non-small-cell bronchopulmonary carcinoma NSCLC-N6-L16 and the epidermoid lung cancer A549. We chose these lines because human non-small-cell bronchopulmonary cancer is the most common type of lung cancer, and because of its difficulty of treatment. Non-small-cell lung cancer has a much slower proliferation time than small-cell lung cancer, which makes chemotherapy very ineffective. In addition, is a type that is difficult to detect and readily gives metastasis, which makes surgery almost impossible. The IC50 (50\% inhibitory concentration test) showed that rinderol had a very clear growth inhibition capacity, with an IC50 of $1.2 \mu \mathrm{g} / \mathrm{mL}$ against the NSCLC-N6-L16 line and $0.9 \mu \mathrm{g} / \mathrm{mL}$ against the A549 line, respectively (Table 2).

Therefore, in comparison with the tested extracts, rinderol showed high cytotoxicity towards both examined cell lines (Table 2), while the IC50 value of vinorelbine (control) amounted to 0.04 and $0.001 \mu \mathrm{g} / \mathrm{mL}$ in A549 and NSCLC-N6-L16 cells, respectively.

The n-hexane extract of post-culture medium displayed cytotoxic potential (IC50 values 12.7 and $13.6 \mu \mathrm{g} / \mathrm{mL}$, respectively). The cytotoxic activity of the methanol extract of in vitro shoots showed weaker activity (IC50 16.6 and $22.7 \mu \mathrm{g} / \mathrm{mL}$, respectively). Rinderol exhibited comparable cytotoxic activity to previous results [6] against HCT-116 (colorectal carcinoma), HL-60 (human promyelocytic leukemia), and HeLa (cervical cancer), as well as comparable cytotoxicity to acetylshikonin, which revealed IC50 values against human hepatocellular carcinoma and mouse Lewis lung carcinoma cell lines ranging from $2.72 \pm 0.38$ to $6.82 \pm 1.5 \mu \mathrm{g} / \mathrm{mL}$ [22]. Moreover, it was recently reported that shikonin in human A549 lung cancer cells $(1-2.5 \mu \mathrm{g} / \mathrm{mL})$ reduced cell viability, while at concentrations of $5-10 \mu \mathrm{g} / \mathrm{mL}$ it induced apoptosis [23], confirming the antitumor potential of naphthoquinone chemical structures. 


\subsection{Continuous Growth Kinetics}

Furthermore, continuous growth kinetics was used to determine the mode of action of rinderol against NSCLC-N6-L16 and A549 lines treated with pure metabolite. The results of continuous kinetics on the NSCLC-N6-L16 line (Figure 3a) showed a slowdown in cell growth in a dose-dependent manner and then a complete cessation of growth during treatment with rinderol. These effects were less visible on the A549 line, but there was a significant effect on cell growth between treatment at $0.75 \mu \mathrm{g} / \mathrm{mL}$ and that at $1 \mu \mathrm{g} / \mathrm{mL}$. The continuous growth kinetics for the NSCLC-N6-L16 line showed a profile of cytostatic antiproliferative activity (Figure 3a), while the treatment with rinderol on the A549 line showed a non-cytostatic antiproliferative activity (Figure $3 b$ ). This clearly proves that the tested molecule cannot act on the same signaling pathways for the two lines.

Table 2. Results of cytotoxicity on human lung cancer cell lines (IC50) of R. graeca in vitro cultivated shoots and hairy roots extracts, pure rinderol, and vinorelbine.

\begin{tabular}{ccc}
\hline IC50 $(\mu \mathrm{g} / \mathrm{mL})$ & A549 & NSCLC-N6-L16 \\
\hline n-Hexane extract of in vitro hairy roots & $12.7 \pm 0.4$ & $13.6 \pm 0.80$ \\
\hline Methanol extract of in vitro shoots & $16.6 \pm 3.1$ & $22.7 \pm 0.20$ \\
\hline Rinderol & $0.9 \pm 0.12$ & $1.2 \pm 0.10$ \\
\hline Vinorelbine & $0.04 \pm 0.94$ & $0.001 \pm 0.04$ \\
\hline
\end{tabular}

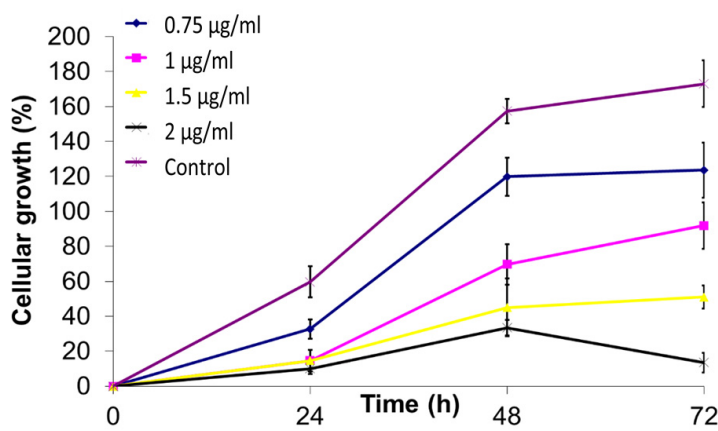

(a) NSCLC-N6-L16 cell line treated by rinderol

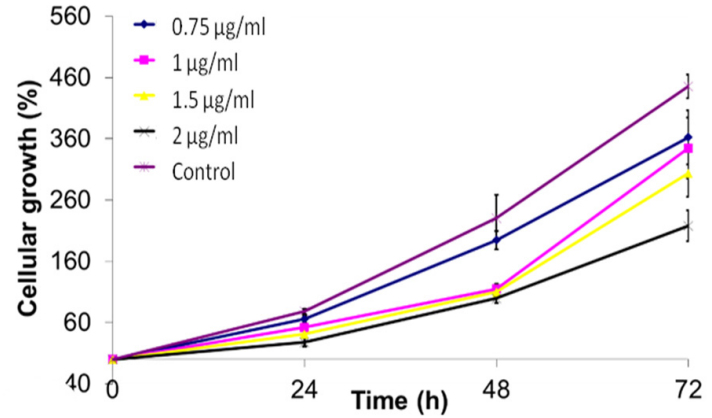

(b) A549 cell line treated by rinderol

Figure 3. Result of continuous growth kinetics of NSCLC-N6-L16 (a) and the line A549 (b) cell lines after treatment with different concentrations of rinderol in a period of $72 \mathrm{~h}$.

\subsection{Antimicrobial Activity}

The antibacterial activity of all extracts and the isolated furane-naphthoquinone rinderol was examined against a panel of six Gram (-) and Gram (+) human pathogenic bacteria strains, as well as three fungi of the Candida genus. The strongest activity was revealed from the pure red pigment of rinderol. This was followed by the n-hexane extracts from cultivated in vitro roots (post-culture media), which was a rich source of rinderol, and the third-highest activity was exhibited by the $\mathrm{MeOH}$ extracts (from in vitro shoots and natural aerial parts). The highest activity was observed against Gram-positive strains (Staphylococcus aureus and Staphylococcus epidermidis (MIC $0.98 \times 10^{-2}-1.18 \mu \mathrm{g} / \mathrm{mL}$ ) (Table 3). 
Table 3. Results of antimicrobial activities (minimum inhibitory concentration (MIC) values) of all tested extracts and pure metabolites $(\mu \mathrm{g} / \mathrm{mL})$.

\begin{tabular}{|c|c|c|c|c|c|c|c|c|c|}
\hline & 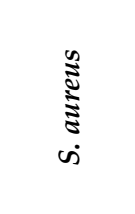 & 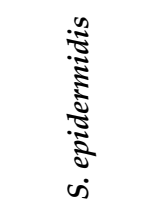 & 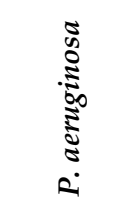 & 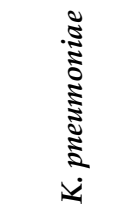 & 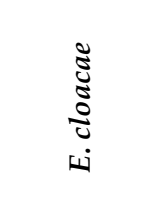 & ن & 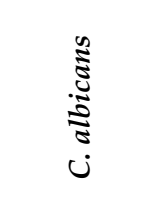 & 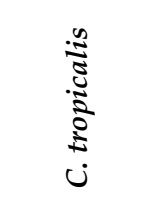 & $\begin{array}{c}\frac{0}{0} \\
\frac{5}{0} \\
\frac{5}{0} \\
ن\end{array}$ \\
\hline $\begin{array}{l}\text { Hexane ex- } \\
\text { tract of in } \\
\text { vitro hairy } \\
\text { roots }\end{array}$ & 0.68 & 0.50 & 1.90 & 2.25 & 2.12 & 1.98 & 1.98 & 1.70 & 1.55 \\
\hline $\begin{array}{c}\text { MeOH ex- } \\
\text { tract of in } \\
\text { vitro shoots }\end{array}$ & 1.18 & 1.12 & 2.50 & 2.97 & 2.45 & 2.42 & 3.10 & 2.65 & 2.38 \\
\hline Rinderol & $1.2 \times 10^{-2}$ & $0.98 \times 10^{-2}$ & $12 \times 10^{-2}$ & $10 \times 10^{-2}$ & $0.95 \times 10^{-2}$ & $0.8 \times 10^{-1}$ & 1.10 . & 0.97 & 0.80 \\
\hline $\begin{array}{l}\text { MeOH ex- } \\
\text { tract aerial } \\
\text { parts }\end{array}$ & 0.88 & 0.76 & 2.3 & 2.50 & 2.20 & 2.33 & 2.87 & 2.48 & 2.27 \\
\hline Netilmicin & $3.5 \times 10^{-3}$ & $3.8 \times 10^{-3}$ & $7.4 \times 10^{-3}$ & $8.3 \times 10^{-3}$ & $7.2 \times 10^{-3}$ & $3.45 \times 10^{-3}$ & - & - & - \\
\hline Amoxicillin & $2 \times 10^{-3}$ & $1.8 \times 10^{-3}$ & $2 \times 10^{-3}$ & $2 \times 10^{-3}$ & $2.5 \times 10^{-3}$ & $2 \times 10^{-3}$ & - & - & - \\
\hline $\begin{array}{c}\text { 5-Flucytosin } \\
\mathrm{e} \\
\end{array}$ & - & - & - & - & - & - & $0.15 \times 10^{-3}$ & $0.95 \times 10^{-3}$ & $9.5 \times 10^{-3}$ \\
\hline $\begin{array}{c}\text { Amphoteri- } \\
\text { cin B }\end{array}$ & - & - & - & - & - & - & $1.20 \times 10^{-3}$ & $0.49 \times 10^{-3}$ & $0.5 \times 10^{-3}$ \\
\hline
\end{tabular}

\section{Materials and Methods}

\subsection{Standards and Chemicals}

Analytical reagents were commercially obtained from Sigma-Aldrich (Steinheim, Germany), Fluka (Göteborg, Sweden), Acros Organics (Fair Lawn, NJ, USA), Merck (Darmstadt, Germany), and Riedel-de-Haen (Darmstadt, Germany). All chemical solvents were of HPLC grade or distilled, commercially obtained from LAB-SCAN (Dublin, Ireland), Panreac (Barcelona, Spain), Fisher-Scientific (Loughborough, UK). All chemicals and reagents, if not stated otherwise, were purchased from Sigma-Aldrich (Athens, Greece and Poznan, Poland).

\subsection{Plant Material and Methanolic Extract Preparation}

Rindera graeca shoot and root in vitro cultures were initiated from seeds donated by Prof I. Chinou, collected in 05/2014 from Mt. Parnon (Arcadia, Peloponnese, Greece) [8].

\subsection{Shoot Cultures}

Seedlings germinated on hormone-free, half-strength basal MS [21] solid medium $(1 / 2 \mathrm{MS})$ in dark at $25 \pm 2{ }^{\circ} \mathrm{C}$. Next, the multiplication of shoots was carried out on solid DCR medium [24] supplemented with $0.5 \mathrm{mg} / \mathrm{L}$ 6-benzylaminopurine, in 12/12 $\mathrm{h}$ day/night light regime at $25 \pm 2{ }^{\circ} \mathrm{C}$. Shoot cultures were performed in $300 \mathrm{~mL}$ Erlenmeyer flasks containing $50 \mathrm{~mL}$ of the relevant medium, and plant material was transferred to fresh media every four weeks. Collected for further phytochemical investigation, shoots (Figure 4a) were lyophilized, powdered, and subjected to extraction.

\subsection{Hairy Root Cultures}

The four-week-old shoots were infected with Agrobacterium rhizogenes strain ATCC 15834 according to the procedure described by Pietrosiuk et al. [25]. Emerging from the places of inoculation, hairy roots were cut off and placed separately into $100 \mathrm{~mL}$ Erlenmeyer flasks containing $30 \mathrm{~mL}$ of liquid hormone-free DCR medium with the addition of 
cefotaxime $(500 \mathrm{mg} / \mathrm{L})$ and cultivated for two weeks to remove bacteria form their tissues. From the established 60 hairy root lines, two root lines, $\operatorname{RgKT} 7$ and $\operatorname{RgKT} 17$, were used for further investigations. PCR analysis confirmed the incorporation of rolB and rolC genes of $A$. rhizogenes into the root tissue. Next, hairy roots were cultivated in liquid hormone free DCR medium on horizontal shaker at $105 \mathrm{rpm}$ (INFORS, Basel, Switzerland) at $23 \pm 1{ }^{\circ} \mathrm{C}$ in the dark, in $250 \mathrm{~mL}$ Erlenmeyer flasks containing $50 \mathrm{~mL}$ of the medium, with subculture to fresh medium every four weeks [26,27]. Collected for further phytochemical investigation, hairy roots (Figure $4 \mathrm{~b}$ ) were lyophilized, powdered, and subjected to extraction.

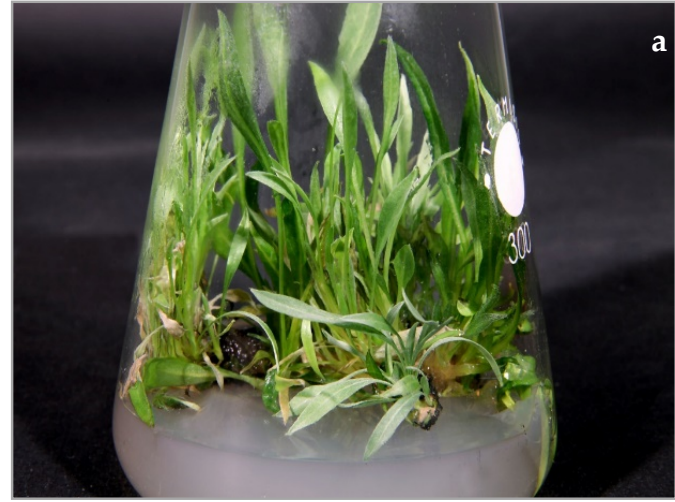

(a)

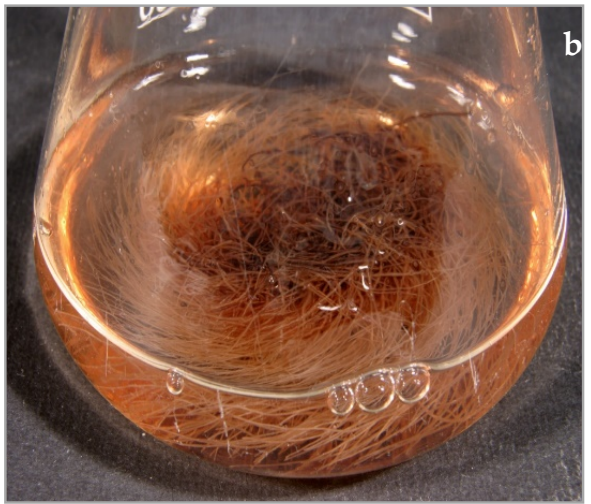

(b)

Figure 4. Rindera graeca in vitro culture: (a) shoots cultivated on solid DCR medium supplemented with BAP $0.5 \mathrm{mg} / \mathrm{L} ;(\mathbf{b})$ hairy roots maintained in liquid DCR medium.

\subsection{Extract Preparation}

The lyophilized and powdered plant material (shoots and hairy roots) was subjected to phytochemical investigations. Shoot extraction performed with methanol was carried out for 15 min using ultrasonic bath (Sonorex, Bandelin, Germany) and incubated overnight on an INFORS horizontal shaker $(105 \mathrm{rpm})$ at $23 \pm 1{ }^{\circ} \mathrm{C}$ in the dark. Afterwards, the samples were centrifugated, re-extracted using methanol, and supernatants were combined and evaporated to dryness. The root tissues were sonicated with n-hexane for 15 min multiple times to perform exhaustive extraction. The resulting root extracts were combined and evaporated to dryness. The thus-prepared shoot and root extracts were stored at $-20^{\circ} \mathrm{C}$ before further analysis.

\subsection{Phytochemical Analysis}

\subsubsection{Chromatographic Fractionation of In Vitro Shoots}

An amount of $2 \mathrm{~g}$ of the methanolic extract was subjected to molecular weight chromatography using a $30 \mathrm{~cm}$ column $(\varnothing: 2 \mathrm{~cm})$ with a Sephadex LH-20 (Pharmacia) stable phase and an isocratic 9:1 MeOH/CH $2 \mathrm{Cl}_{2}$ mobile phase; 58 fractions were obtained. After visualization using thin layer chromatography (stable phase: cellulose plate, mobile phase: $85 / 15 \mathrm{H}_{2} \mathrm{O} / \mathrm{CH}_{3} \mathrm{COOH}$, visualization agent: Naturstoff), seven compounds (caffeic acid $(8.4 \mathrm{mg})$, chlorogenic acid $(8 \mathrm{mg})$, rosmarininc acid $(11 \mathrm{mg})$, lithospermic acid $(5 \mathrm{mg})$, rabdosiin (3 $\mathrm{mg})$, disodium rabdosiin salt $(2 \mathrm{mg})$, and quercetin 3-rutinoside-7-rhamnoside $(7 \mathrm{mg})$ ) were detected and compared with our compound library and further purified through preparative TLC (Supplementary). Their structures were confirmed through NMR analysis and comparison with literature data [8]. 


\subsubsection{Chromatographic Fractionation of In Vitro Hairy Roots}

An amount of $1.5 \mathrm{~g}$ of the Rindera graeca n-hexane extract was subjected to column chromatography on $2.5 \mathrm{~g}$ silica gel $(0.015-0.040 \mathrm{~mm})$ eluted with cyclohexane $/ \mathrm{CH}_{2} \mathrm{Cl}_{2}$ and $\mathrm{CH}_{2} \mathrm{Cl}_{2} / \mathrm{MeOH}$ step gradient, yielding fourteen fractions. The fractions were chromatographed on TLC aluminum plates and the fraction $\mathrm{rg} 9(4 \mathrm{mg})$ yielded rinderol which was structurally confirmed by NMR spectroscopy (Supplementary) and comparison with literature data [6].

The purity for each isolated compound was approx. $\geq 90 \%$ according to NMR spectra.

\subsubsection{Analysis of Pyrrolizidine Alkaloids (PAs)}

For the isolation and identification of PAs from Rindera graeca aerial parts (Supplementary), the BfR [28] method was used: $2 \mathrm{~g}$ of dried plant material was macerated in 20 $\mathrm{mL} \mathrm{H}_{2} \mathrm{SO}_{4} 0.05 \mathrm{M}$ for $15 \mathrm{~min}$ under sonication. Then, the macerate was centrifuged for 10 $\mathrm{min}$ at $3800 \mathrm{rpm}$ and the upper liquid layer was extracted. This process was repeated once. The final extract was neutralized to $\mathrm{pH} 7$ and filtrated.

The presence of PAs was confirmed through the Mattocks/Molyneux method, first applying a $10 \%$ acetic anhydride solution in benzene/naphtha $4: 5$ and then Ehrlich chemical agent on a silica TLC plaque which was developed in an 88:5:2 $\mathrm{CH}_{2} \mathrm{Cl}_{2} / \mathrm{MeOH} / \mathrm{NH}_{4} \mathrm{OH}$ system. The PAs were visualized as purple spots [8].

\section{3,6,4. Liquid Chromatography/Mass Spectrometry (LC/MS) Analysis of PAs}

The PA/PANO extract was examined by qualitative LC/MS analysis. The scientific equipment used was an Agilent 6500 Series Accurate-Mass Quadrupole Time-of-Flight (Agilent Technologies Inc., Santa Clara, CA, USA) device equipped with ESI-Jet Stream ion source and Atlantis HILIC silica column $(150 \times 2.1 \mathrm{~mm}, \mathrm{dp}=3 \mu \mathrm{m})$ (Waters, Milford, MS, USA). The chromatograph used a diode array detector autosampler, dual grading pump, and column heater. An RP18 stable phase was used in conjunction with a gradient elution mobile phase of $0.1 \%$ formic acid in methanol with a stable flow of $0.25 \mathrm{~mL} / \mathrm{min}$. For this particular experiment the MS scans were acquired in positive ionization mode.

\subsubsection{Nuclear Magnetic Resonance (NMR) Analysis}

Samples of the abovementioned metabolites were dissolved in NMR-grade $\mathrm{D}_{2} \mathrm{O}$ and $\mathrm{CDCl}_{3}$ as a solvent and TMS as an internal standard utilized for ${ }^{1} \mathrm{H}-\mathrm{NMR}$ analysis, using a Bruker DRX 400 (400 MHz) instrument (Bruker, Rheinstetten, Germany). After examination of the received spectra with analysis software and comparison with available reference data, the compounds were fully determined.

\subsection{Biological Activities}

\subsubsection{Cytotoxicity Determinations}

All cell lines were cultured in RPMI 1640 medium with 5\% fetal calf serum, to which were added $100 \mathrm{IU}$ penicillin $\mathrm{mL}^{-1}, 100 \mu \mathrm{g}$ streptomycin $\mathrm{mL}^{-1}$, and $2 \mathrm{mM}$ glutamine, at 37 ${ }^{\circ} \mathrm{C}$ in an air/carbon dioxide atmosphere $(95: 5, v / v)$. Cytotoxicity was determined by continuous drug exposure. Experiments were performed in 96-well microtiter plates $\left(10^{5}\right.$ cells/mL for NSCLC-N6-L16 and $2 \times 10^{-4}$ cells mL $\mathrm{mL}^{-1}$ for A549). Cell growth was estimated by a colorimetric assay based on the conservation of tetrazolium dye (MTT) to a blue formazan product by live mitochondria. Eight repeats were performed for each concentration. Control growth was estimated from eight determinations. Vinorelbine ditartrate salt hydrate was used as positive control in experiments. Optical density at $570 \mathrm{~nm}$ corresponding to solubilized formazan was read for each well on a Titertek Multiskan MKII [29]. 


\subsubsection{Microorganism Cultures}

A panel of microorganisms, including two Gram-positive bacteria, Staphylococcus aureus (ATCC 25923) and Staphylococcus epidermidis (ATCC 12228); four Gram-negative bacteria, Escherichia coli (ATCC 25922), Enterobacter cloacae (ATCC 13047), Klebsiella pneumoniae (ATCC 13883), and Pseudomonas aeruginosa (ATCC 227853); as well as three pathogenic fungi, Candida albicans (ATCC 10231), Candida tropicalis (ATCC 13801), and Candida glabrata (ATCC 28838) were used. The standard antibiotics netilmicin and amphotericin B were used in order to control the tested bacteria and fungi [29].

\subsubsection{Determination of Antimicrobial Activity}

The antimicrobial activities of the crude extracts and the isolated compounds were determined using the agar dilution technique [27]. For all assays, stock solutions of the tested samples were prepared at $10 \mathrm{mg} / \mathrm{mL}$. Serial dilutions of the stock solutions in broth medium $(100 \mu \mathrm{L}$ of Mueller Hinton broth or on Sabouraud broth for the fungi) were prepared in a microtiter plate (96 wells). Then, $1 \mu \mathrm{L}$ of the microbial suspension (the inoculum, in sterile distilled water) was added to each well. For each strain, the growth conditions and the sterility of the medium were checked and the plates were incubated as stated above. MICs were determined as the lowest concentrations preventing visible growth. The standard antibiotics netilmicin, amoxicillin, and clavulanic acid (at concentrations $4-88 \mu \mathrm{g} / \mathrm{mL}$ ) were used in order to control the sensitivity of the tested bacteria, while amphotericin B and 5-fluocytocine (at concentrations $0.4-1 \mu \mathrm{g} / \mathrm{mL}$ ) were used as controls against the tested fungi (Sanofi Diagnostics Pasteur). For each experiment, any pure solvent used was also applied as blind control. The experiments were repeated three times and the results were expressed as average values.

\section{Conclusions}

Rindera graeca, a rare Greek endemic plant, could be efficiently micropropagated in in vitro cultures. The in vitro cultivated plant material was studied phytochemically for the first time and several secondary metabolites were identified, consisting of six caffeic acid derivatives, one flavonol glycoside (quercetin-3-rutinoside-7-rhamnoside), and a rare furano-naphthoquinone (rinderol).

The chemical profiles of in vitro cultures and the plant in nature were comparable, rich in phenolic metabolites, and the same PAs were identified. It is noteworthy that the naphthoquinone rinderol was detected and isolated only from in vitro cultures, while the quercetin diglycoside rutin was absent.

$\mathrm{n}$-Hexane and methanol extracts, as well as pure rinderol, were tested against human non-small-cell bronchopulmonary carcinoma cell line NSCLC-N6-L16 and the epidermoid lung cancer cell line A549, and rinderol revealed strong activity, which was further evaluated with continuous growth kinetics for its potential mode of action. The results showed that rinderol did not act in a comparable manner against both tested cancer cell lines, as it exerted a dose-dependent cytostatic activity only against NSCLC-N6-L16. Due to the very interesting results, further antiproliferative studies are under development.

All extracts and rinderol studied for their antibacterial activity showed strong activity against Gram-positive S. aureus and S. epidermidis strains.

Rindera graeca in vitro cultures could serve as a reasonable source of very important caffeic derivatives, bioactive quercetin-triglycoside, and the unique naphthoquinone rinderol. The present study confirms the beneficial potential of in vitro root cultures for the production of essential secondary metabolites, and indicates that they could serve as a source towards a sustainable approach for the production of bioactive compounds for further research and applications. 
Supplementary Materials: The following are available online at www.mdpi.com/2223-7747/10/5/834/s1.

Author Contributions: Conceptualization, K.G., I.C. and K.S.-B.; methodology, K.G., A.P, M.J., C.R., and I.C.; investigation, H.D., C.G., K.S.-B., M.J., and C.R.; data curation, K.G., K.S.-B., and C.G.; writing-original draft preparation, I.C., K.G., C.G., and C.R.; writing-review and editing, K.G., C.G., K.S.-B., A.P., M.J., and C.R.; supervision, I.C. All authors have read and agreed to the published version of the manuscript.

Funding: This research received no external funding.

Data Availability Statement: In this section, please provide details regarding where data supporting reported results can be found, including links to publicly archived datasets analyzed or generated during the study. Please refer to suggested Data Availability Statements in section "MDPI Research Data Policies" at https://www.mdpi.com/ethics. You might choose to exclude this statement if the study did not report any data.

Acknowledgments: In this section, you can acknowledge any support given which is not covered by the author contribution or funding sections. This may include administrative and technical support, or donations in kind (e.g., materials used for experiments).

Conflicts of Interest: The authors declare no conflicts of interest.

\section{References}

1. Sykłowska-Baranek, K.; Pietrosiuk, A.; Graikou, K.; Damianakos, H.; Jeziorek, M.; Chinou, I. Phenolic compounds from in vitro cultures of Rindera graeca Boiss. \& Feldr. Planta Med. 2013, 79, PI27, doi:10.1055/s-0033-1352117.

2. Damianakos, H.; Jeziorek, M.; Sykłowska-Baranek, K.; Buchwald, W.; Pietrosiuk, A.; Chinou, I. Pyrrolizidine alkaloids from Cynoglossum columnae Ten. (Boraginaceae). Phytochem. Lett. 2016, 15, 234-237, doi:10.1016/j.phytol.2016.02.005.

3. Damianakos, H.; Sotiroudis, G.; Chinou, I. Chemical constituents from the aerial parts of Onosma erecta. J. Nat. Prod. 2013, 76, 1829-1835.

4. Orfanou, I.M.; Damianakos, H.; Bazos, I.; Graikou, K.; Chinou, I. Pyrrolizidine Alkaloids from Onosma kaheirei Teppner (Boraginaceae). Rec. Nat. Prod. 2016, 10, 221-227.

5. Tufa, T.; Damianakos, H.; Zengin, G.; Graikou, K.; Chinou, I. Antioxidant and enzyme inhibitory activities of disodium rabdosiin isolated from Alkanna sfikasiana Tan, Vold and Strid. S. Afr. J. Bot. 2019, 120, 157-162.

6. Jeziorek, M.; Damianakos, H.; Kawiak, A.; Laudy, A.E.; Zakrzewska, K.; Sykłowska-Baranek, K.; Chinou, I.; Pietrosiuk, A. Bioactive rinderol and cynoglosol isolated from Cynoglossum columnae Ten. in vitro root culture. Ind. Crops Prod. 2019, 137, 446-452, doi:10.1016/j.indcrop.2019.04.046.

7. Varvouni, E.-F.; Zengin, G.; Graikou, K.; Ganos, C.; Mroczek, T.; Chinou, I. Phytochemical analysis and biological evaluation of the aerial parts from Symphytum anatolicum Boiss. and Cynoglottis barrelieri (All.) Vural \& Kit Tan (Boraginaceae). Biochem. Syst. Ecol. 2020, 92, 104128.

8. Ganos, C.; Aligiannis, N.; Chinou, I.; Naziris, N.; Chountoulesi, M.; Mroczek, T.; Graikou, K. Rindera graeca (Boraginaceae) phytochemical profile and biological activities. Molecules 2020, 25, 3625 doi:10.3390/molecules25163625.

9. Varvouni, E.-F.; Zengin, G.; Graikou, K.; Ganos, C.; Mroczek, T.; Chinou, I. Chemical profile and biological properties of the endemic Turkish species Phyllocara aucheri. S. Afr. J. Bot. 2021, 137, 340-344.

10. Mandić, B.M.; Simić, M.R.; Vučković, I.M.; Vujisić, L.V.; Novaković, M.M.; Trifunović, S.S.; Nikolić-Mandić, S.D.; Tešević, V.V.; Vajs, V.V.; Milosavljević, S.M. Pyrrolizidine alkaloids and fatty acids from the endemic plant species Rindera umbellata and the effect of lindelofine-N-oxide on tubulin polymerization. Molecules 2013, 18, 10694-10706.

11. Bulgakov, V.P.; Inyushkina, Y.V.; Fedoreyev, S.A. Rosmarinic acid and its derivatives: Biotechnology and applications. Crit. Rev. Biotechnol. 2012, 32, 203-217, doi:10.3109/07388551.2011.596804.

12. Yildirim, H. A new Rindera (Boraginaceae) species from Western Anatolia, Turkey. Phytotaxa 2019, 427, $249-258$.

13. Civra, A.; Francese, R.; Sinato, D.; Donalisio, M.; Cagno, V.; Rubiolo, P.; Ceylan, R.; Uysal, A.; Zengin, G.; Lembo, D. In vitro screening for antiviral activity of Turkish plants revealing methanolic extract of Rindera lanata var. lanata active against human rotavirus. BMC Complement. Altern. Med. 2017, 17, 74.

14. Yücel, T.B.; Karaoğlu, Ş.A.; Yaylı, N. Antimicrobial activity and composition of Rindera lanata (LAM.) Bunge var. canescens (ADC) Kosn. Essential oil obtained by hydrodistillation and microwave assisted distillation. Rec. Nat. Prod. 2017, 11, 328-333.

15. Yuldasheva, N.K.; Ul'chenko, N.T.; Glushenkova, A.I. Lipids from fruit of Rindera oblongifolia. Chem. Nat. Compd. 2012, 47, 981-982.

16. Fu, P.P.; Xia, Q.; Lin, G.; Chou, M.W. Pyrrolizidine Alkaloids. Genotoxicity, Metabolism Enzymes, Metabolic Activation, and Mechanisms. Drug Metab. Rev. 2004, 36, 1-55.

17. Wiedenfeld, H. Plants containing pyrrolizidine alkaloids: Toxicity and problems. Food Add. Contamin. Part A 2011, $28,282-292$.

18. Mandic, B.M.; Vlajic, M.D.; Trifunovic, S.S.; Simic, M.R.; Vujisic, L.V.; VuČkovic, I.M.; Novakovic, M.M.; Nikolic Mandic, S.D.; Teevic, V.V.; Vajs, V.V.; et al. Optimisation of isolation procedure for pyrrolizidine alkaloids from Rindera umbellata Bunge. Nat. Prod. Res. 2015, 29, 887-890. 
19. Akramov, S.T.; Kiyamitdinova, F.; Yunusov, S.Y. Alkaloids of Rindera cyclodonta, R. echinata, and Heliotropium dasycarpum. Chem. Nat. Compd. 1967, 3, 244-244, doi:10.1007/BF00564140.

20. Dias, M.I.; Sousa, M.J.; Alves, R.C.; Ferreira, I.C.F.R. Exploring plant tissue culture to improve the production of phenolic compounds: A review. Ind. Crops Prod. 2016, 82, 9-22, doi:10.1016/j.indcrop.2015.12.016.

21. Dong, M.; Liu, D.; Li, Y.-H.; Chen, X.-Q.; Luo, K.; Zhang, Y.-M.; Li, R.-T. Naphthoquinones from Onosma paniculatum with Potential Anti-inflammatory Activity. Planta Med. 2017, 83, 631-635, doi:10.1055/s-0042-120545.

22. Xiong, W.; Luo, G.; Zhou, L.; Zeng, Y.; Yang, W. In vitro and in vivo antitumor effects of acetylshikonin isolated from Arnebia euchroma (Royle) Johnst (Ruanzicao) cell suspension cultures Chin. Med. 2009, 4, 14, doi:10.1186/1749-8546-4-14.

23. Yeh, Y.-C.; Liu, T.-J.; Lai, H.-C. Shikonin induces apoptosis, necrosis, and premature senescence of human A549 lung cancer cells through upregulation of p53 expression. Evid. Based Complement. Altern. Med. 2015, 620383, doi:10.1155/2015/620383.

24. Gupta, P.K.; Durzan, D.J. Shoot multiplication from mature trees of Douglas-fir (Pseudotsuga menziesii) and sugar pine (Pinus lambertiana). Plant Cell Rep. 1985, 4, 177-179, doi:10.1007/BF00269282.

25. Pietrosiuk, A.; Sykłowska-Baranek, K.; Wiedenfeld, H.; Wolinowska, R.; Furmanowa, M.; Jaroszyk, E. The shikonin derivatives and pyrrolizidine alkaloids in hairy root cultures of Lithospermum canescens (Michx.) Lehm. Plant Cell Rep. 2006, 25, 1052-1058, doi:10.1007/s00299-006-0161-2.

26. Sykłowska-Baranek, K.; Pietrosiuk, A.; Szyszko, E.; Graikou, K.; Jeziorek, M.; Kuźma, Ł.; Chinou, I. Phenolic compounds from in vitro cultures of Rindera graeca Boiss. \& Heldr. Planta Med. 2012, 78, PI342, doi:10.1055/s-0032-1321029.

27. Sykłowska-Baranek, K.; Pietrosiuk, A.; Kuźma, Ł.; Chinou, I.; Kongel, M.; Jeziorek, M. Establishment of Rindera graeca transgenic root culture as a source of shikonin derivatives. Planta Med. 2008, 74, PG54, doi:10.1055/s-0028-1084806.

28. BfR (German Federal Institute for Risk Assessment). Determination of Pyrrolizidine Alkaloids (PA) in Plant Material by SPE-LC-MS/MS. Method Protocol, BfR-PA-Tea-2.0/2014. $2014 . \quad$ Available online: https://www.bfr.bund.de/cm/349/determination-of-pyrrolizidine-alkaloids-pa-in-plant-material.pdf (01/04/2021).

29. Michalakea, E.; Graikou, K.; Aligiannis, N.; Panoutsopoulos, G.; Kalpoutzakis, E.; Roussakis, C.; Chinou, I. Isolation and structure elucidation of secondary metabolites of two Greek endemic Inula species. Biological activities Phytochem. Letts. 2019, $31,155-160$. 